Article

\title{
Optimization of Oleuropein and Luteolin-7-O-Glucoside Extraction from Olive Leaves by Ultrasound-Assisted Technology
}

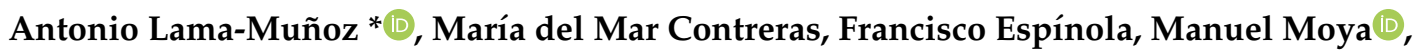 \\ Inmaculada Romero and Eulogio Castro \\ Department of Chemical, Environmental and Materials Engineering, University of Jaén, Campus Las Lagunillas, \\ s/n, Building B3, 23071 Jaén, Spain \\ * Correspondence: alama@ujaen.es; Tel.: +34-953-211-860
}

Received: 29 May 2019; Accepted: 27 June 2019; Published: 28 June 2019

\begin{abstract}
The olive orchard cultivation in Mediterranean countries results in huge amounts of lignocellulosic biomass residues. One of the main residues are olive leaves. Olive leaves contain high concentrations of bioactive antioxidant compounds like oleuropein and luteolin-7-glucoside. The production of biactive compounds from olive leaves requires treatments capable of breaking the lignocellulosic structure. Current research focuses on use of inexpensive, quick, and not harmful to the environment treatments, searching a more simplified large-scale operation approach. Recently, advances in applied chemistry have led to possible new emerging industrial techniques like ultrasound-assisted extraction (UAE). This technology is a promising candidate as a green treatment solution for olive leaves utilization in a biorefinery. However, this application goes through prior optimization of technique and operating conditions. The goal of this study was to optimize the extraction of oleuropein and luteolin-7-glucoside from olive leaves through an investigation of the influence of key factors of ultrasound-assisted extraction using an experimental central composite design, in comparison with conventional Soxhlet extraction. The highest extraction efficiency and antioxidant capacity were obtained under optimal increment of temperature and amplitude conditions $\left(40{ }^{\circ} \mathrm{C}\right.$ and $30 \%$, respectively). Values for oleuropein, luteolin-7-glucoside were $69.91 \mathrm{~g} / \mathrm{kg}$ and $1.82 \mathrm{~g} / \mathrm{kg}$, respectively.
\end{abstract}

Keywords: antioxidants; bioactive compounds; biorefinery; experimental design; olive leaves; olive biomass; response surface methodology; ultrasound-assisted extraction; olive byproducts valorization

\section{Introduction}

The activity of the olive oil industry generates enormous quantities of solid wastes; among them olive leaves represent $10 \%$ of the total weight of the olives harvested. They are also generated in high amounts during olive tree pruning (25 kg per olive tree annually) [1]. Disposal of olive leaves help to maintain fields clean and avoid the spread of diseases; they are usually removed by either burning or grinding and scattering them on fields, which involves a very important problem of management and environmental pollution [2]. Nowadays there are no exploitations on an industrial scale for this byproduct, so proposals for evaluation and exploitation can help its better use and valorization.

Olive leaves represent a promising raw source of antioxidants and bioactive substances. Olive leaves contain high amounts of a large variety of phenolic and flavonoid compounds (hydroxytyrosol, verbascoside, apigenin-7-glucoside, rutin, and ligstroside, among others), similar to those present in olives and their derived products [3,4]. Because of that, there is a great interest by the scientific community in the valorization of these residues to achieve extracts enriched in these compounds that 
can be used in food, cosmetic, and pharmaceutical industries [5,6] to prevent oxidation processes. In addition, olive leaves extracts have other applications in food industry such as to improve the nutritive value of certain foods [7]. Among the bioactive compounds of olive leaves are secoiridoids and flavonoids, oleuropein and the flavone luteolin-7-glucoside being some of the compounds that have attracted more interest and which show well-documented biologic activities including antioxidant, antimicrobial, anti-inflammatory, anticancer, and neuroprotective properties [8]. Oleuropein and luteolin-7-glucoside are the most important phenolic compounds recovered from olive leaves [9]. Oleuropein is the most abundant component of the secoiridoid fraction, whereas glycosylated form luteolin-7-glucoside is the principal flavonoid with concentrations can reach up to 210 and $11 \mathrm{~g} / \mathrm{kg}$ dry leaf, respectively $[10,11]$.

Literature shows that oleuropein has potent biological and pharmacological activities [12]. Its main pharmacological properties that make it anticancer, anti-diabetes, antiobesity, cardioprotective, gastroprotective, hepato-protective, and radioprotective, among others, are in large part attributed to its putative antioxidant and anti-inflammatory effects [13]. Oleuropein and luteolin-7-glucoside have also been studied for their differentiation-inducing effects on hematopoietic stem cells highlighting their potential use in the ex vivo generation of blood cells components that are very important for the therapy of a wide spectrum of hematological disorders [14]. In a work carried out by Ahmad-Qasem et al. [15] on the olive leaves extracts' bioaccessibility, luteolin-7-glucoside was the most stable polyphenol during the in vitro digestion process simulation which means this compound may be considered as one of the responsible of the bioactivity of olive leaves extracts. Therefore, owing to their numerous health benefits associated, an optimized extraction method is important for their isolation and purification, thus contributing to the advances in research of their biological properties.

Several extraction technologies have been used to obtain antioxidant extracts and to isolate bioactive compounds from olive leaves [16]. The optimization of the extraction techniques for these compounds is essential for the development of biorefineries dedicated to the valorization of the by-products generated by olive biomass for obtaining pharmaceuticals, cosmetics, nutraceuticals, and functional foods. The conventional or traditional methods such as Soxhlet solid-liquid extraction have many drawbacks, such as long extraction times and exposure of the extracts to excessive heat. Recently, the demand of novel techniques of extraction with shorter extraction times and less consumption of solvent than conventional methods is increasing. As an alternative of traditional extraction methods, newer and more sophisticated technologies such as pressurized liquid extraction, also known as accelerated solvent extraction, microwave-assisted extraction, plasma-assisted extraction, supercritical fluid extraction, and ultrasound-assisted extraction (UAE) have been developed and used to obtain different types of bioproducts from various biomass [17]. For instance, pressurized liquid extraction has shown to be effective for the recovery of olive leaves biophenols [18]; microwave treatment has been utilized for the extraction of lipids from lyophilized algal biomass [19]; plasma-based processes have been used as pretreatment for the isolation of biopolymers from crustacean wastes [20], and supercritical carbon dioxide extraction is suited for the obtaining of hop extracts mostly constituted by non-polar compounds [21]. Specifically, the UAE process is an effective extraction technology for a broad range of compounds from different samples of biomass [22] and is being specifically used in the extraction of phenolic antioxidant and bioactive compounds from olive leaves [23-26] and other olive oil industry by-products $[27,28]$. UAE provides many advantages for natural compounds extraction since ultrasound waves produce intense pressure and temperature gradients within the material, which can induce physical structural disruption of cell wall due to the formation of microcavities. This then enhances the extraction rates by increasing the mass transfer and release of intracellular components into the extraction solvent, leading to higher extraction yields with shorter processing time [23]. The application of UAE in food industry is an interesting alternative to the traditional extraction methods. It is considered one of the most economically and feasible large-scale applications [29].

UAE is influenced by several factors such as temperature and amplitude (maximum height of a soundwave). Therefore, the optimization of the extraction procedure is critical to produce extracts 
with high content of oleuropein and luteolin-7-O-glcuoside. Experimental designs are useful tools for evaluation of statistical significance of the factors implicated and the simultaneous optimization of variables. In comparison to one-variable-at-a-time protocol, the experimental design reduces the experimental trials, analysis time, and the environmental and economic cost and error [30]. Experimental design under response surface methodology (RSM) is a useful mathematical and statistical protocol to assess the influence of multiple factors and their interactions on one or more response variables. RSM has been used by many authors for optimization of bioactive compounds extraction from a number of biomass sources, including olive leaves, using UAE [31].

Although the effect of extraction conditions on the oleuropein content has been investigated, no study reports on the effects of UAE extraction factors on the recovery and simultaneous optimization of the other main polyphenol from the olive leaves extracts, the compound luteolin-7-glucoside. Optimization of UAE has been studied by extraction parameters including solid/solvent ratio, time, and ethanol concentration. However, most of the authors did not include temperature and/or amplitude as design factors [32-34]. Thus, the goal of this study was to optimize the extraction of oleuropein and luteolin-7-glucoside from olive leaves through a study of the influence of two key factors of UAE such as increment of temperature and amplitude using a central composite design (CCD). Additionally, antioxidant capacity of the extracts as well as the total phenolic content (TPC) and total flavonoid content (TFC) were also included. Furthermore, these findings were compared to the traditional Soxhlet extraction method.

\section{Materials and Methods}

\subsection{Samples and Reagents}

Olive tree leaves from Picual variety were manually picked from specimens situated on the campus Las Lagunillas of the University of Jaén, Spain. After collection, raw material was dried in an oven for $24 \mathrm{~h}$ at $105{ }^{\circ} \mathrm{C}$ and ground using a cutting mill featuring a $5 \mathrm{~mm}$ sieve. The average particle diameter by mass was further evaluated $\left(\mathrm{D}_{50}=1.21 \mathrm{~mm}\right)$. Finally, they were stored at room temperature in the dark until extraction. For determining the moisture content, a sample of fresh olive leaves was weighed, heated in an oven for $24 \mathrm{~h}$ at $105^{\circ} \mathrm{C}$, cooled in a desiccator, and then reweighed to constant weight in accordance with NREL analytical procedure (Technical Report NREL/TP-510-42621). Total solids and moisture content in fresh olive leaves expressed on weight basis were $51.44 \%(\mathrm{w} / \mathrm{w})$ and $48.56 \%(\mathrm{w} / \mathrm{w})$, respectively.

Acetonitrile, ethanol, and methanol (HPLC grade) were supplied by PanReac AppliChem (Barcelona, Spain). Commercial standards of oleuropein and luteolin-7-glucoside were provided by Sigma-Aldrich (St. Louis, USA).

\subsection{Extraction Methods}

Two methods were evaluated for the extraction of oleuropein and luteolin-7-glucoside from olive leaves.

Soxhlet extraction was carried out with $10 \mathrm{~g}$ of dry olive leaves and $150 \mathrm{~mL}$ of $60 \%(\mathrm{v} / \mathrm{v})$ ethanol-water solution for $4 \mathrm{~h}$. Literature shows that the aqueous ethanol solutions are required to effectively extract phenolic compounds from olive leaves $[26,32,35]$. Since aqueous ethanol solutions are the most common safe solvents in the food industrial process, they were selected as extraction solvent. The extractions were performed in triplicate. The extracts were filtered at the end of the experiments using grade 1 Whatman ${ }^{\circledR}$ qualitative filter paper. The results were expressed in mean \pm standard deviation.

Ultrasound-assisted extraction (UAE) was performed using a sonifier ultrasonic disrupter/ homogenizer 150 (Branson Ultrasonics Corporation, Danbury, USA) operating at a frequency of $40 \mathrm{kHz}$, equipped with a microtip ultrasound probe, and a temperature probe. Specifically, $2.0 \mathrm{~g}$ ground olive leaves were thoroughly mixed with $26 \mathrm{~mL}$ of $60 \%$ (v/v) ethanol-water solution (solvent/solid ratio 
of 13:1 v/w) in a glass beaker. The extraction was performed with the ultrasonic probe immersed $1 \mathrm{~cm}$ into the mixture. Before applying ultrasonics, all samples were put into a thermostatic bath at $20{ }^{\circ} \mathrm{C}$ and maintained there until this temperature was reached. When an ultrasound pulse travels through sample, some of the energy is absorbed by the sample and is converted to heat, which in turn produces a temperature rise. The heating rate depends on the amplitude. Amplitude is a parameter used to describe the strength of an ultrasound pulse. Amplitude is a measure of a wave's magnitude of oscillation, that is, the magnitude of the maximum disturbance in the medium. Since sample heating occurs due to absorption of ultrasound energy by the solution and to self-heating of the probe, the extraction procedure was performed in maximum temperature mode and continuous sonics (continuous sonics were run at a set constant amplitude, until a set maximum temperature was measured by the temperature probe, time the assay was terminated). The increment of temperature was used as a design factor and the ultrasonics time was considered as a response to be studied. The effects of these UAE parameters were evaluated on the oleuropein and luteolin-7-glucoside content from olive leaves extracts. An ethanol-water $(60 \%, v / v)$ solution was used as extraction solvent. This solvent is commonly used for extracting under optimal conditions phenolic compounds from olive leaves [25] because it is a non-harmful, low-toxicity, and easily removable solvent that presents minimum environmental impact and was a good option for the UAE process.

\subsection{Design of Experiments and Statistical Analysis}

RSM was applied to the investigation of the effects of the factors increment of temperature and amplitude on the extraction of phenolic and flavonoid compounds from olive leaves. As the equipment cannot operate at more than $70 \%$ the maximum amplitude when using a microtip, in this design a range between $30 \%$ and $60 \%$ of maximum amplitude was selected. Seven responses were selected: the extraction yield or residual dry matter (R), total flavonoid and phenolic contents (TFC and TPC, respectively), antioxidant capacity (2,2-diphenyl-1-picrylhydroazyl (DPPH) free-radical scavenging capacity), oleuropein and luteolin-7-glucoside contents of the extracts, and applied ultrasonic time to reach the maximum temperature. To determine the relationships between the factors and observed results and to optimize the operating conditions, a design of experiments was performed: a central composite design (CCD) involving two factors, consisting of thirteen randomized trials, and including five replicates of the central point. The coded and actual factors for the experimental design are listed in Table 1, together with the maximum temperature reached by the sample. The factors were coded in accordance with the transformation reported by Vidal et al. [36].

As temperature is not an independent factor of the amplitude, the increment of temperature from $20{ }^{\circ} \mathrm{C}$ was fixed as independent variable in experimental design. As mentioned in Section 2.2, prior to the extraction, all samples were tempered at $20^{\circ} \mathrm{C}$. The sonifier allowed us to control the way in which ultrasonics were applied to the samples by setting the unit to operate in one of the several different modes. Maximum temperature control mode was determined and specified operating temperatures for each ultrasonic cycle. Several maxima allowable temperatures in the samples or liquids were set for the experimental design $\left(40,50\right.$ and $\left.60^{\circ} \mathrm{C}\right)$, so that ultrasonics stopped automatically when the specified temperatures were reached and measured by the temperature probe.

The experimental data were evaluated using the Design-Expert@ $®$ 8.0.7.1 software (Stat-Ease, Inc., USA) and response surface methodology. ANOVA test was used to analyze the significance of the data. To explain the behavior of the responses, a quadratic model for each response was used in accordance with Equation (1):

$$
Y=\beta_{0}+\beta_{1} \cdot \Delta T+\beta_{2} \cdot A+\beta_{12} \cdot \Delta T \cdot A+\beta_{11} \cdot \Delta T^{2}+\beta_{22} \cdot A^{2}+S D
$$

where $\mathrm{Y}$ is the response, $\Delta \mathrm{T}$ is the coded increment of temperature $\left({ }^{\circ} \mathrm{C}\right), \mathrm{A}$ is the coded amplitude, and $\mathrm{SD}$ is the standard deviation of the models. The predicted responses were correlated with the following set of coefficients: the intercept $\left(\beta_{0}\right)$, linear $\left(\beta_{1}\right.$ and $\left.\beta_{2}\right)$, interaction $\left(\beta_{12}\right)$, and quadratic $\left(\beta_{11}\right.$ and $\beta_{22}$ ) coefficients. A significance level of $0.1 \%$ was set up for the models (p-value $<0.001$ ) and a $5 \%$ 
for the coefficients ( $p$-value $<0.05$ ). The lack of fit was statistically significant at the $10 \%$ probability level ( $p$-value $>0.1$ ). The terms not significant of the models were not incorporated to the equations in accordance with the $\mathrm{p}$-values indicated above.

Table 1. Central composite design (CCD) expressed in terms of actual and coded factors used for optimization of ultrasound-assisted extraction (UAE) conditions and maxima operating temperatures.

\begin{tabular}{|c|c|c|c|c|c|c|}
\hline \multirow{2}{*}{ Run } & \multirow{2}{*}{ Space Type } & \multicolumn{2}{|c|}{ Increment of Temperature $(\Delta T)$} & \multirow{2}{*}{$\begin{array}{c}\text { Maximum } \\
\text { Temperature }\left({ }^{\circ} \mathrm{C}\right)\end{array}$} & \multicolumn{2}{|c|}{ Amplitude (A) } \\
\hline & & Actual $\left({ }^{\circ} \mathrm{C}\right)$ & Coded & & Actual (\%) ${ }^{1}$ & Coded \\
\hline 1 & Center & 30 & 0 & 50 & 45 & 0 \\
\hline 2 & Axial & 30 & 0 & 50 & 23.8 & -1.413 \\
\hline 3 & Factorial & 20 & -1 & 40 & 60 & 1 \\
\hline 4 & Axial & 30 & 0 & 50 & 66.2 & 1.413 \\
\hline 5 & Factorial & 40 & 1 & 60 & 30 & -1 \\
\hline 6 & Axial & 15.9 & -1.410 & 35.9 & 45 & 0 \\
\hline 7 & Center & 30 & 0 & 50 & 45 & 0 \\
\hline 8 & Center & 30 & 0 & 50 & 45 & 0 \\
\hline 9 & Factorial & 20 & -1 & 40 & 30 & -1 \\
\hline 10 & Axial & 44.1 & 1.410 & 64.1 & 45 & 0 \\
\hline 11 & Factorial & 40 & 1 & 60 & 60 & 1 \\
\hline 12 & Center & 30 & 0 & 50 & 45 & 0 \\
\hline 13 & Center & 30 & 0 & 50 & 45 & 0 \\
\hline
\end{tabular}

\subsection{Extraction Yield}

To obtain the extraction yield, the extracts were filtered through a $0.45 \mu \mathrm{m}$ and an amount of $2 \mathrm{~mL}$ was dried using an electronic moisture analyzer model BMO35 (BOECO, Germany) at $105^{\circ} \mathrm{C}$ to constant weight. The extraction yields are referred to initial dry biomass and expressed as grams of extract per kilogram of dry olive leaf.

\subsection{TPC and TFC of Olive Leaves Extracts}

For the TPC quantification of the olive leaves extracts the Folin-Ciocalteu method was used. Briefly, $1.5 \mathrm{~mL}$ of $0.2 \mathrm{M}$ Folin's reagent and $1.2 \mathrm{~mL}$ of $0.7 \mathrm{M}$ sodium carbonate solution were added to $300 \mu \mathrm{L}$ of a suitably diluted aliquot of the extracts. The sample was maintained at $25^{\circ} \mathrm{C}$ in the dark for $10 \mathrm{~min}$, and then absorbance was measured at $655 \mathrm{~nm}$. The results were expressed as mmol Gallic acid equivalents/kg dry olive leaf (mmol GAE/kg).

The TFC of the olive leaves extracts was evaluated using the method described by Chang et al. [37] with modifications. In brief, $1 \mathrm{~mL}$ of extract was reconstituted to $1 \mathrm{~mL}$ with methanol-water $20 \%(\mathrm{v} / \mathrm{v})$. After $5 \mathrm{~min}$ of incubation, $0.3 \mathrm{~mL}$ of $10 \%(\mathrm{w} / \mathrm{v}) \mathrm{AlCl}_{3}$ and $0.3 \mathrm{~mL} 5 \%(\mathrm{w} / \mathrm{v}) \mathrm{NaNO}_{2}$ solutions were added. The sample was allowed to stand for $6 \mathrm{~min}$. Then, $2 \mathrm{~mL}$ of a $1 \mathrm{M} \mathrm{NaOH}$ solution was added, and the final volume of the mixture was brought to $10 \mathrm{~mL}$ using double-distilled water. The sample was allowed to stand for $15 \mathrm{~min}$, and its absorbance was measured at $510 \mathrm{~nm}$. The TFC was evaluated from a calibration curve. The results were expressed as mmol Rutin equivalents $/ \mathrm{kg}$ dry olive leaf (mmol RE/kg).

\subsection{Antioxidant Capacities of Olive Leaves Extracts}

The DPPH free-radical scavenging method described by Vázquez-Roncero et al. [38] was used for determining the antioxidant capacity of the extracts. The inhibition percentage of the DPPH radicals was measured at $515 \mathrm{~nm}$ after $15 \mathrm{~min}$ in accordance with the following Equation (2):

$$
\% \text { DPPHinhibition }=\frac{[D P P H] \text { control }-[D P P H] \text { extract }}{[D P P H] \text { control }} 100
$$

The DPPH concentrations ([DPPH]) were calculated by interpolating the calibration curve of absorbance versus DPPH concentration. The inhibition percentage was transformed into antioxidant 
capacity using Trolox as external standard. For this purpose, another calibration curve graphing the percentage of inhibition against the Trolox concentration was used. The antioxidant capacity of the extracts was expressed as mmol Trolox equivalents $/ \mathrm{kg}$ dry olive leaf (mmol TE/kg).

\subsection{Analysis of Phenolic Compounds by HPLC-DAD}

The determination of oleuropein and luteolin-7-glucoside in olive leaves extracts were carried out in accordance with the COI method (COI/T.20/Doc No 29/Rev.1, 2017) for the determination of biophenols with modifications. HPLC quantification was performed on a Shimadzu Prominence UFLC chromatograph system equipped with an autosampler, a column oven, a degasser, a diode array detector, and a quaternary pump. A C18 reverse-phase column $(250 \mathrm{~mm} \times 4.6 \mathrm{~mm})$, type BDS HYPERSIL $5 \mu \mathrm{m}$ (Thermo Fisher Scientific Inc., USA) was used at $30{ }^{\circ} \mathrm{C}$ to separate the biophenols. Oleuropein and luteolin-7-glucoside were identified by comparison with their commercial standards through retention times and the UV absorption spectra in the 190-350 nm range. Quantification was carried out by integration of the peaks at $280 \mathrm{~nm}$ using five-point regression curves of individual stock solutions of known concentration in triplicate of external standards. The phenolic compounds contents were expressed as g polyphenol $/ \mathrm{kg}$ dry olive leaves (g polyphenol $/ \mathrm{kg}$ ).

\section{Results and Discussion}

\subsection{Influence of UAE Factors on the Extraction of Bioactive Compounds from Olive Leaves}

Extraction procedure is a very important stage for the recovery and isolation of bioactive compounds from olive leaves. Although the effect of UAE operating conditions on the extraction yield, total phenolic and flavonoid contents, and antioxidant capacity has been studied, few works have reported the influence of extraction factors on the recovery of specific phenolic compounds from olive leaves $[23,25,33]$ using UAE and RSM, at least from our knowledge of literature, and only one of them tackled the task of how to simultaneously optimize the recovery of some of the main phenolic compounds found in olive leaves extracts (verbascoside and luteolin-4'-O-glucoside) besides oleuropein, but without taking into account amplitude as a factor to study [39]. In order to obtain the maximum extraction yield of oleuropein and luteolin-7-glucoside, two of the key factors involved in the UAE technique such as the increment of temperature, or maximum operating temperature, and amplitude were examined in this study. CCD and RSM were used to perform the tests and interpret the experimental results and optimize the operating conditions of this technique. The experimental design is presented in Table 1. The time duration of the ultrasonic processing needed to reach the maxima temperatures was measured and can be seen in Table 2.

Table 2. Responses for the central composite design obtained of the extractions by $\mathrm{UAE}^{1}$.

\begin{tabular}{|c|c|c|c|c|c|c|c|}
\hline Run & $\begin{array}{l}\text { Ultrasonic } \\
\text { Time (min) }\end{array}$ & $\underset{(\mathrm{g} / \mathrm{kg})}{R}$ & $\begin{array}{c}\text { TPC (mmol } \\
\text { GAE/kg) }\end{array}$ & $\begin{array}{c}\text { TFC (mmol } \\
\text { RE/kg) }\end{array}$ & $\begin{array}{c}\text { DPPH (mmol } \\
\text { TE/kg) }\end{array}$ & $\begin{array}{l}\text { Oleuropein } \\
\text { (g/kg) }\end{array}$ & $\begin{array}{l}\text { Luteolin-7- } \\
\text { Glucoside (g/kg) }\end{array}$ \\
\hline 1 & 5.05 & $244.2^{1}$ & 178.1 & 211.0 & 182.9 & 58.2 & 1.46 \\
\hline 3 & 2.00 & 190.7 & 146.1 & 170.2 & 146.2 & 47.3 & 1.15 \\
\hline 4 & 3.00 & 227.9 & 160.1 & 191.3 & 158.1 & 52.3 & 1.31 \\
\hline 5 & 17.93 & 292.9 & 212.8 & 261.0 & 213.8 & 71.5 & 1.87 \\
\hline 7 & 5.13 & 256.0 & 186.3 & 223.4 & 183.2 & 62.2 & 1.56 \\
\hline 8 & 5.55 & 248.1 & 177.9 & 212.1 & 175.0 & 58.9 & 1.46 \\
\hline 9 & 5.82 & 209.5 & 156.3 & 185.6 & 156.8 & 51.0 & 1.26 \\
\hline 10 & 9.27 & 312.4 & 215.9 & 266.1 & 214.6 & 71.6 & 1.88 \\
\hline 11 & 4.98 & 283.5 & 197.2 & 239.4 & 198.8 & 65.3 & 1.67 \\
\hline
\end{tabular}

${ }^{1}$ Data were expressed per kilogram of dry leaf. 
Table 2 also summarizes the influence of temperature and amplitude on R, TPC, TFC, DPPH, and oleuropein and luteolin-7-glucoside contents of olive leaves extracts by UAE and shows experimental values obtained all of the responses for each the design runs. The oleuropein content ranged from $44.9 \mathrm{~g} / \mathrm{kg}$ to $71.6 \mathrm{~g} / \mathrm{kg}$ dry leaf. As for luteolin-7-glucoside content, the quantity changed between $1.08 \mathrm{~g} / \mathrm{kg}$ and $1.88 \mathrm{~g} / \mathrm{kg}$ dry leaf. The highest values of oleuropein and luteolin-7-glucoside (runs 5 and 10) was in agreement with the best results of TPC, TFC, and DPPH, showing that these polyphenols can also be the main compounds responsible for the antioxidant capacity of the obtained extracts.

Increment of Temperature and Amplitude Influence

The mathematical models based on the experimental results for each of the responses are showed in the Table 3. Analysis of variance in accordance with the p-values stated in Section 2.3 showed that the models were reliable for prediction of responses.

Table 3. Mathematical models displayed in coded factors describing the behavior of the responses, including the main statistical parameters.

\begin{tabular}{cccc}
\hline Response & Models & $\mathbf{R}^{\mathbf{2}}$ & CV (\%) \\
\hline Time $(\mathrm{min})$ & $5.17+3.64 \cdot \Delta \mathrm{T}-4.12 \cdot \mathrm{A}-2.28 \cdot \Delta \mathrm{TA}+1.01 \cdot \Delta \mathrm{T}^{2}+1.69 \mathrm{~A}^{2} \pm 0.33$ & $0.997^{1}$ & $5.13^{2}$ \\
$\mathrm{R}(\mathrm{g} / \mathrm{kg})$ & $249.86+44.00 \Delta \mathrm{T}-6.05 \cdot \mathrm{A}-6.87 \cdot \mathrm{A}^{2} \pm 3.82$ & 0.992 & 1.56 \\
$\mathrm{TPC}(\mathrm{mmol} \mathrm{GAE} / \mathrm{kg})$ & $180.53+27.13 \cdot \Delta \mathrm{T}-6.83 \cdot \mathrm{A}-4.24 \cdot \mathrm{A}^{2} \pm 3.55$ & 0.984 & 2.00 \\
$\mathrm{TFC}(\mathrm{mmol} \mathrm{RE} / \mathrm{kg})$ & $216.01+37.27 \cdot \Delta \mathrm{T}-8.25 \cdot \mathrm{A}-5.47 \cdot \mathrm{A}^{2} \pm 5.43$ & 0.980 & 2.56 \\
$\mathrm{DPPH}(\mathrm{mmol} \mathrm{TE} / \mathrm{kg})$ & $180.48+27.66 \cdot \Delta \mathrm{T}-7.00 \cdot \mathrm{A}-4.41 \cdot \mathrm{A}^{2} \pm 4.75$ & 0.973 & 2.67 \\
Oleuropein $(\mathrm{g} / \mathrm{kg})$ & $59.60+9.55 \cdot \Delta \mathrm{T}-2.39 \cdot \mathrm{A}-1.63 \cdot \mathrm{A}^{2} \pm 1.53$ & 0.977 & 2.61 \\
Luteolin-7-glucoside $(\mathrm{g} / \mathrm{kg})$ & $1.50+0.28 \cdot \Delta \mathrm{T}-0.074 \cdot \mathrm{A}-0.033 \cdot \mathrm{A}^{2} \pm 0.040$ & 0.982 & 2.68 \\
\hline & ${ }^{1}$ Coefficient of determination ${ }^{2}{ }^{2}$ Coefficient of variation. & &
\end{tabular}

When setting the amplitude and the temperature increase as operating factors, the operating time is variable and is interpreted as response, so that the model in Table 3 shows the existing interrelation between the three variables. As it is deduced from the model, the time increases with $\Delta \mathrm{T}$ and decreases with the amplitude and shows a small positive curvature with both factors. In addition, there is a negative interaction between the factors so that at the lower ends of one factor the action of the other increases. Thus, for $\mathrm{A}=-1$ the coefficient of $\Delta \mathrm{T}$ becomes +5.92 and for $\mathrm{A}=+1$ its value is +1.36 , which indicates that for low amplitudes the heating speed is low and for high amplitudes the speed is high (Figure 1). Likewise, for the amplitude, if $\Delta \mathrm{T}$ is set at its value -1 the coefficient of $\mathrm{A}$ is -1.84 , the time slowly decreases with the increase of $\mathrm{A}$, and for $\Delta \mathrm{T}=+1$ the coefficient is -6.40 , the decrease in time is considerably higher than in the previous case. The greater the amplitude, the higher the heating rate and the shorter the time needed to reach a certain temperature.

For the rest of the responses in the Table 3, both increment of temperature and amplitude were statistically significant factors. The effects of interaction between the factors did not show to be statistically significant. As it can be seen, only linear terms and quadratic effect of amplitude resulted as significant. These data are quite consistent with those reported in a previous work [23] in which the quadratic terms of the amplitude were significant for the responses TPC and TFC measured in olive mill leaves extracts. In all models, except for time, $\Delta \mathrm{T}$ is the most important factor by several orders of magnitude. This indicates that, for these responses, it is much more important to increase temperature than to decrease amplitude, although with low amplitudes the responses are improved.

Since time and temperature are dependant on each other in UAE, optimizing the increment of temperature and/or maximum temperature makes it possible to reduce extraction time. In the case of UAE, in general, it has been reported that an increase in temperature from 20 to $70{ }^{\circ} \mathrm{C}$ correlates with enhancements in extraction yields of the phenolic compounds from olive leaves as well as occurs in other biomass compared to non-ultrasonicated extractions [22]. This is owing to the induction of matrix bonds ruptures, the increase of the compound solubility, solvent diffusion rate, mass transfer, and reduction in viscosity of the solvent [31]. Effectively, in this work a positive correlation was observed between all responses and the increment of temperature, which was the most influential 
factor, indicated that the responses were directly proportional to the temperature reached. A similar positive effect of temperature on total polyphenols recovery and antioxidant capacity from olive leaves has been also described by other authors [3,25].

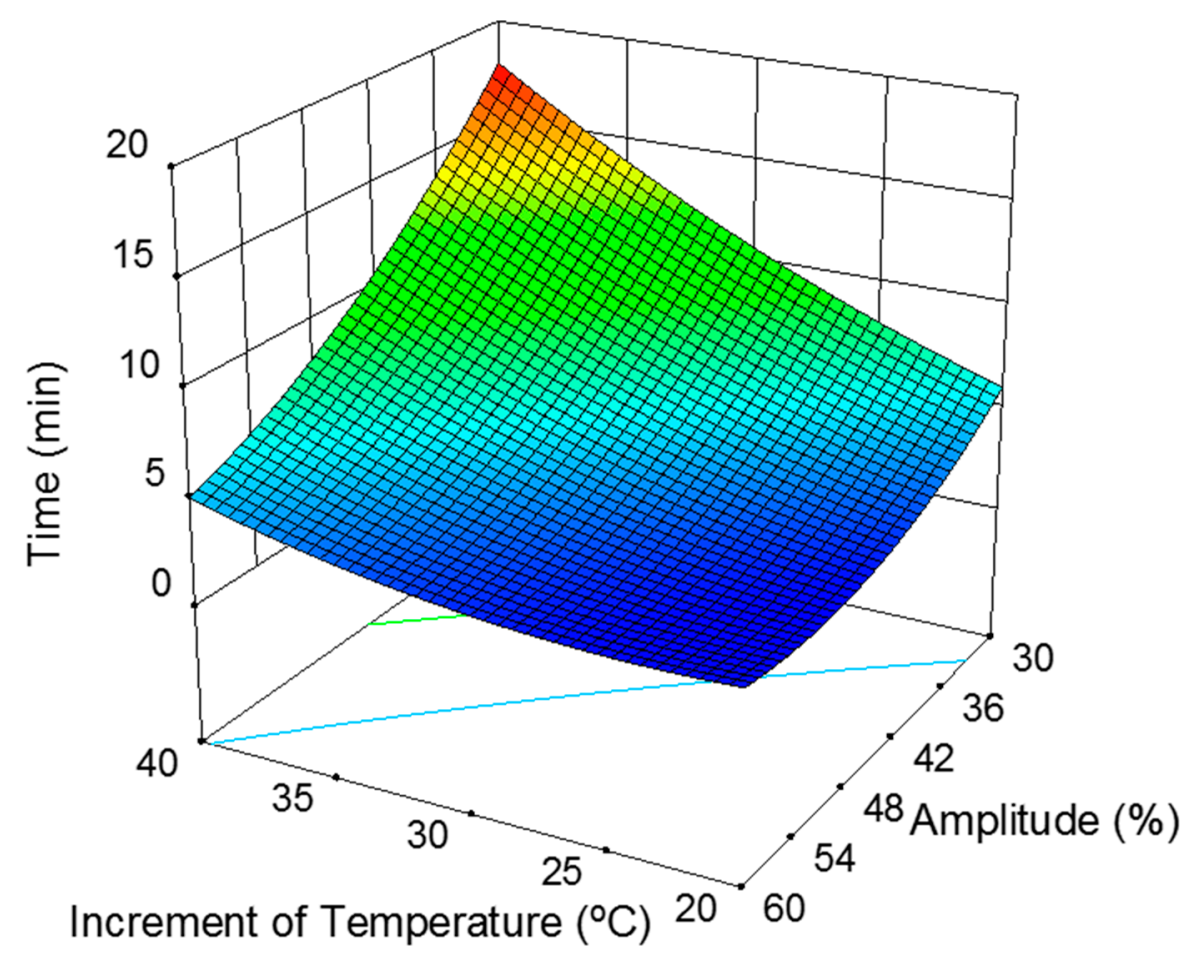

Figure 1. Variation of ultrasonic process duration time with increment of temperature and amplitude during processing of olive leaves by UAE.

In the ultrasonic system used in this work, the system with a coupled probe, amplitude plays an important role in the extraction since the number of compression cycles of ultrasonics depends on it. However, in this work its influence was less significant and showed a negative correlation with all responses slightly decreasing with increasing amplitude. It was observed that high amplitudes resulted in solvent agitation instead of cavitation, and as a consequence in low transmission of the ultrasounds through the liquid media.

The analysis of the simultaneous effects of the independent factors on the responses can also be seen on 3D response surface curves. Response surface plots were constructed in accordance with the equations of the predicted models (Table 3). Figure 2 presents the response surface graphs showing the combined influence of increment of temperature and amplitude on the oleuropein and luteolin-7-glucoside contents. Increment of temperature during extraction process was the most significant factor and the responses linearly increased with raising temperature, separately from amplitude.

\subsection{Optimization of the UAE Conditions}

The extraction process was optimized by using RSM. A simultaneous numerical optimization of the experimental conditions for all of responses was carried out using the optimization option in Design Expert software to maximize the responses what generated as optimal conditions of increment of temperature and amplitude of $40^{\circ} \mathrm{C}$ (corresponding to a maximum temperature of $60^{\circ} \mathrm{C}$ ) and $30 \%$ (minimum amplitude), respectively (Table 4). 


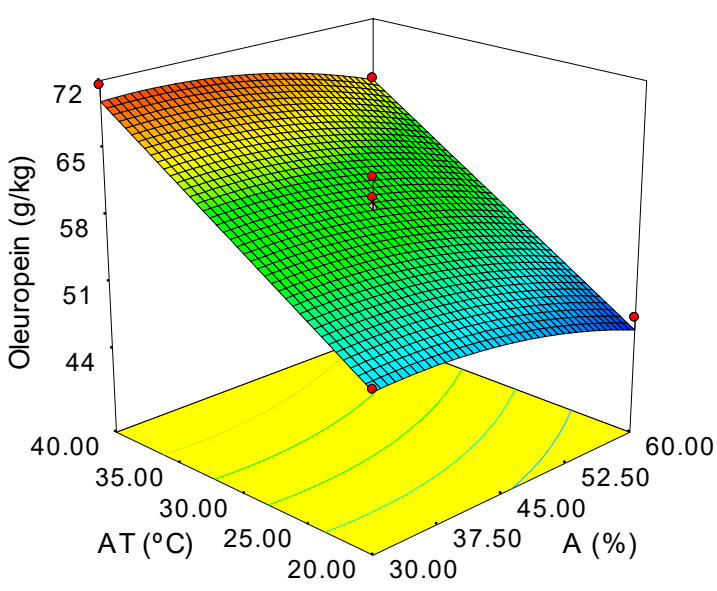

(a)

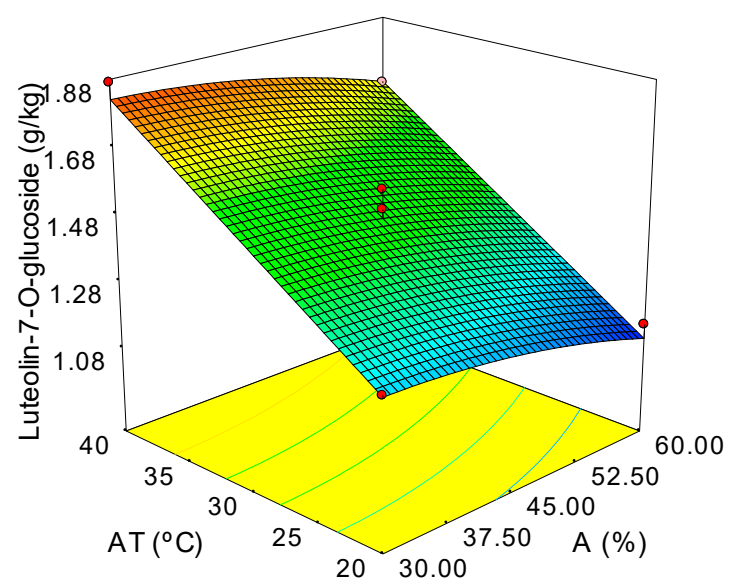

(b)

Figure 2. Response surface analysis for the oleuropein and luteolin-7-glucoside contents from olive leaves extracts with ultrasound-assisted extraction describing the influence of the factors increment of temperature and amplitude. The maxima of the responses are located at $60{ }^{\circ} \mathrm{C}$ and $30 \%$ amplitude.

(a) Model graph for oleuropein content; (b) Model graph for luteolin-7-glucoside content.

Table 4. Comparison of both extraction methods applied in this work.

\begin{tabular}{ccc}
\hline Response & Soxhlet Extraction & Ultrasound-Assisted Extraction $^{{ }^{1}}$ \\
\hline Time $(\mathrm{min})$ & 240 & $17.91 \pm 0.33$ \\
$\mathrm{R}(\mathrm{g} / \mathrm{kg})$ & $368.77 \pm 0.14^{2}$ & $293.06 \pm 3.82$ \\
$\mathrm{TPC}(\mathrm{mmol} \mathrm{GAE} / \mathrm{kg})$ & $251.91 \pm 2.13$ & $210.25 \pm 3.55$ \\
$\mathrm{TFC}(\mathrm{mmol} \mathrm{RE} / \mathrm{kg})$ & $274.97 \pm 4.39$ & $256.07 \pm 5.43$ \\
DPPH $(\mathrm{mmol} \mathrm{TE} / \mathrm{kg})$ & $291.42 \pm 18.80$ & $210.73 \pm 4.75$ \\
Oleuropein $(\mathrm{g} / \mathrm{kg})$ & $65.57 \pm 0.70$ & $69.91 \pm 1.53$ \\
Luteolin-7-glucoside $(\mathrm{g} / \mathrm{kg})$ & $1.32 \pm 0.03$ & $1.82 \pm 0.04$ \\
\hline
\end{tabular}

${ }^{1}$ Optimal values resulted from a simultaneous numerical optimization all of the responses, including time; ${ }^{2}$ Values reported are averages. The results were expressed as means \pm standard deviation of replicate extractions in triplicate.

Other researchers have also proven that the maximum oleuropein content is obtained at an extraction optimal temperature of $60^{\circ} \mathrm{C}[33,39]$. Using optimal conditions, the maxima response values R, TPC, TFC, DPPH, oleuropein and luteolin-7-glucoside contents, and time were theoretically calculated (Table 4). The use of temperatures over the optimum should be avoided owing to the fact they lead to solvent loss by evaporation and may also promote degradation of the compounds of interest which has been reported at higher temperatures and therefore for longer periods of time using UAE [40]. As for the other factor considered for optimization, 30\% of amplitude was also selected as an optimal value by other authors [35] which indicated significant statistical differences when comparing phenolic extraction yields utilizing amplitudes in a range of $20 \%-50 \%$ [41]. Also, as mentioned before, it is important to indicate that high amplitudes can deteriorate the ultrasonic probe, resulting in liquid agitation instead of agitation.

\subsection{Comparison against Soxhlet Conventional Extraction Method}

Phenolic profiles from olive leaves extracts obtained by UAE and Soxhlet are shown in Figure 3. As can be seen, the extracts did not exhibit significant differences in composition, showing similar chromatograms as for the types of compounds observed in each one, although the amounts recovered were different. Oleuropein and luteolin-7-glucoside were the most abundant phenolic and flavonoid compounds in olive leaves extracts. 


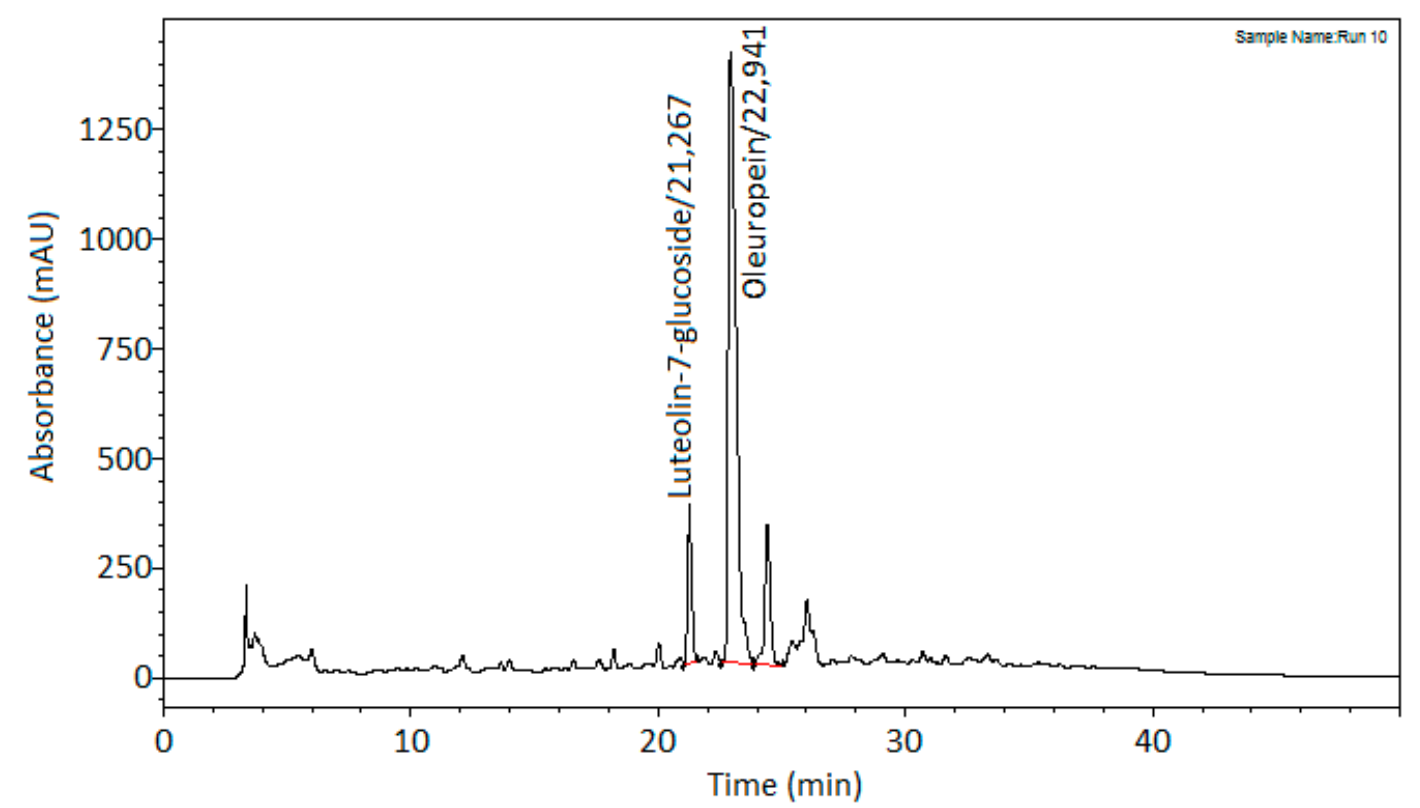

(a)

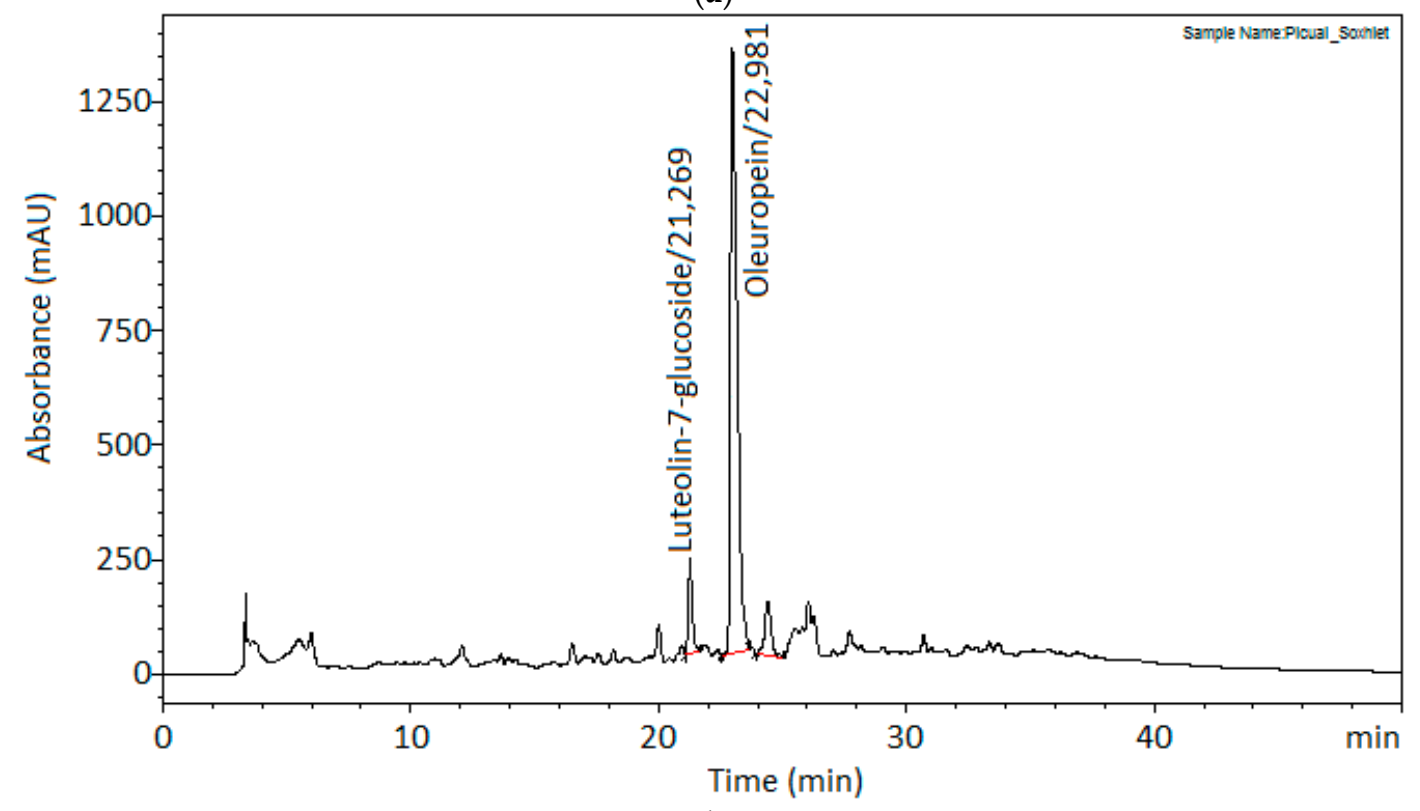

(b)

Figure 3. Representatives HPLC chromatograms recorded at $280 \mathrm{~nm}$ of olive leaves extracts recovered by UAE under the following conditions: $44.1^{\circ} \mathrm{C}$ of $\Delta \mathrm{T}$ and amplitude $45 \%$ (a) and Soxhlet extraction for $4 \mathrm{~h}$; (b) the peaks of oleuropein and luteolin-7-glucoside appear marked in the chromatograms.

Table 4 shows a comparison of the responses obtained by conventional Soxhlet extraction under the conditions described in the Section 2.2 and UAE from a simultaneous numerical optimization all of the responses obtained with an operating conditions of $44.1^{\circ} \mathrm{C}$ of $\Delta \mathrm{T}$ and $30 \%$ of amplitude from CCD stated in Table 1. The best results regarding R, TPC, TFC, and DPPH were reached by Soxhlet method. Based on the differences observed between UAE and Soxhlet extracts in R, TPC, and TFC, it is reasonable to think that Soxhlet extracts may contain other phenolics in higher concentrations than oleuropein and luteolin-7-glucoside but also having solubilized more impurities during the extraction. On the other hand, ultrasounds can ease swelling and hydration, resulting in an expansion in the pores of the cell wall, which enhances the diffusion action, leading to improve mass transfer. However, the second stage which is the limiting step requires additional energy, for example, stirring to quicken 
the extraction procedure. The ultrasonic breakdown of olive leaf matrix by ultrasonics might not be enough. In addition, in the Soxhlet method each cycle of extraction was done with pure solvent which can be another explanation of the better yield of Soxhlet over UAE [42] in these responses.

The extraction method had also a great effect on the amount of the bioactives quantified in this work. In this case, however, if the influence of extraction method on oleuropein and luteolin-7-glucoside contents in the extracts is analyzed, the data indicate that the same trend does not repeat because UAE provides significantly higher contents of both compounds compared to Soxhlet extraction. In the case of oleuropein, UAE extracts $(69.91 \mathrm{~g} / \mathrm{kg})$ showed a $6.6 \%$ significantly higher content than Soxhlet extracts ones $(65.57 \mathrm{~g} / \mathrm{kg})$. With regards to the luteolin-7-glucoside content, significant differences were also found between Soxhlet $(1.32 \mathrm{~g} / \mathrm{kg})$ and UAE extracts $(1.82 \mathrm{~g} / \mathrm{kg})$. UAE extracts exhibited a $37.9 \%$ higher content than Soxhlet ones. Long exposure to temperature for several hours can more likely result in the degradation of these compounds by Soxhlet method. These differences were observed by other researchers; for instance, Cifá et al. [23] optimized the extraction of oleuropein and reported significant increases in extraction yield of oleuropein from $6 \%$ to $84 \%$ compared to traditional maceration and therefore within the range obtained in this work. Several works show the efficiency of the UAE technique compared to conventional methods. In any case, with regards to the content of the quantified bioactive compounds and from a point of view of the purity of the extracts, this should be seen as an advantage in favor of ultrasound-assisted extraction, since in the end purer extracts in oleuropein and luteolin-7-glucoside were obtained.

Although there are many aspects that can influence the extracts composition, like the cultivar and sampling date, the oleuropein content reached in this work was similar than that reported by other authors utilizing the same extraction technique, i.e., ultrasound application. The maximum oleuropein content was $71.65 \mathrm{~g} / \mathrm{kg}$ dry olive leaf versus $65 \mathrm{~g} / \mathrm{kg}$ dry olive leaf determined by Ahmad-Qasem et al. [43].

\section{Conclusions}

During the last decade, the interest in the recovery of bioactive polyphenols from olive leaves has increased in the industry and the scientific community. Oleuropein and luteolin-7-glucoside extraction from olive leaves could add value to this by-product of the olive oil industry if they are recovered by applying efficient extraction technologies. The present work investigated the influence of UAE experimental conditions (increment of temperature and amplitude) on the extraction yield of the two main olive leaf polyphenols, showing a significant increase of oleuropein and luteolin-7-glucoside contents in the extracts (6.6\% and $37.9 \%$, respectively) in comparison to Soxhlet conventional extraction. The extraction samples are heated using ultrasound, so that the greater the amplitude, the higher the heating rate. The optimal results were obtained at low amplitudes and high temperatures. The highest extraction efficiency and antioxidant capacity were obtained under optimal increment of temperature and amplitude conditions $\left(40{ }^{\circ} \mathrm{C}\right.$ and $30 \%$ amplitude). Under these conditions, the simultaneous optimization of oleuropein and luteolin-7-glucoside provided a concentration of oleuropein of $69.91 \mathrm{~g} / \mathrm{kg}$ whilst the concentration of luteolin-7-glucoside was $1.82 \mathrm{~g} / \mathrm{kg}$. The results demonstrated that the UAE is quicker and more efficient than conventional Soxhlet method, providing olive leaves extracts with higher amounts of oleuropein and luteolin-7-glucoside, but significantly reducing the extraction time (around only $15 \mathrm{~min}$ are required versus $4 \mathrm{~h}$ of the traditional extraction) and energy costs. This work can help to approach new studies on the UAE process on a larger scale for later industrial valorization of olive leaves. This process could provide large enough amounts of the bioactive compounds studied which will allow more analyses of their biological activities and improvement in the understanding of their properties.

Author Contributions: Conceptualization, A.L.M., F.E. and M.M.; methodology, A.L.M. and M.d.M.C.; software, M.M.; writing-original draft preparation, A.L.M and M.d.M.C.; writing—review and editing, A.L.M., F.E. and M.M.; supervision, E.C.; project administration, F.E.; funding acquisition, A.L.M., F.E. and I.R. 
Funding: This research was funded by University of Jaén (Acción 6) and Ministerio de Ciencia, Innovación y Universidades of Spanish Government (Project code: ENE2017-85819-C2-1-R).

Acknowledgments: The authors want to thank the technical and human support provided by CICT of the University of Jaén (UJA, MINECO, Junta de Andalucía, FEDER).

Conflicts of Interest: The authors declare no conflict of interest.

\section{References}

1. Rahmanian, N.; Jafaric, S.M.; Wani, T.A. Bioactive profile, dehydration, extraction and application of the bioactive components of olive leaves. Trends Food Sci. Technol. 2015, 42, 150-172. [CrossRef]

2. Cara, C.; Romero, I.; Oliva, J.M.; Sáez, F.; Castro, E. Liquid hot water pretreatment of olive tree pruning residues. Appl. Biochem. Biotechnol. 2007, 136-140, 379-394.

3. Xie, P.; Huang, L.; Zhang, C.; Zhang, Y. Phenolic compositions, and antioxidant performance of olive leaf and fruit (Olea europaea L.) extracts and their structure-activity relationships. J. Funct. Foods 2015, 16, 460-471. [CrossRef]

4. Luque de Castro, M.D.; Priego Capote, F. Extraction of oleuropein and related phenols from olive leaves and branches. In Olives and Olive Oil in Health and Disease Prevention, 1st ed.; Preedy, V., Watson, R., Eds.; Elsevier: Amsterdam, The Netherlands, 2010; Volume 1, pp. 259-273.

5. Rodrigues, F.; Pimentel, F.B.; Oliveira, M.B.P.P. Olive by-products: Challenge application in cosmetic industry. Ind. Crop. Prod. 2015, 70, 116-124. [CrossRef]

6. Nunes, M.A.; Pimentel, F.B.; Costa, A.S.G.; Alves, R.C.; Oliveira, M.B.P.P. Olive by-products for functional and food applications: Challenging opportunities to face environmental constraints. Innov. Food Sci. Emerg. 2016, 35, 139-148. [CrossRef]

7. Žugčić, T.; Abdelkebir, R.; Alcantara, C.; Collado, M.C.; García-Pérez, J.V.; Meléndez-Martínez, A.J.; Jambrak, A.R.; Lorenzo, J.M.; Barba, F.J. From extraction of valuable compounds to health promoting benefits of olive leaves through bioaccessibility, bioavailability and impact on gut microbiota. Trends Food Sci. Technol. 2019, 83, 63-77. [CrossRef]

8. Özcan, M.M.; Matthäus, B. A review: Benefit and bioactive properties of olive (Olea europaea L.) leaves. Eur. Food Res. Technol. 2017, 243, 89-99. [CrossRef]

9. Vogel, P.; Machado, I.K.; Garavaglia, J.; Zani, V.T.; de Souza, D.; Dal Bosco, S.M. Polyphenols benefits of olive leaf (Olea europaea L.) to human health. Nutr. Hosp. 2015, 31, 1427-1433. [CrossRef]

10. Şahin, S.; Elhussein, E.; Bilgin, M.; Lorenzo, J.M.; Barba, F.J.; Roohinejad, S. Effect of drying method on oleuropein, total phenolic content, flavonoid content, and antioxidant activity of olive (Olea europaea) leaf. J. Food Process. Pres. 2018, 1-10. [CrossRef]

11. Talhaoui, N.; Taamalli, A.; Gómez-Caravaca, A.M.; Fernández-Gutiérrez, A.; Segura-Carretero, A. Phenolic compounds in olive leaves: Analytical determination, biotic and abiotic influence, and health benefits. Food Res. Int. 2015, 70, 92-108. [CrossRef]

12. Salem, M.B.; Affes, H.; Ksouda, K.; Sahnoun, Z.; Zeghal, K.M.; Hammami, S. Pharmacological activities of Olea europaea leaves. J. Food Process. Pres. 2015, 39, 3128-3136. [CrossRef]

13. Hassen, I.; Casabianca, H.; Hosni, K. Biological activities of the natural antioxidant oleuropein: Exceeding the expectation-A mini-review. J. Funct. Foods 2015, 18, 926-940. [CrossRef]

14. Samet, I.; Villareal, M.O.; Motojima, H.; Han, J.; Sayadi, S.; Isoda, H. Olive leaf components apigenin 7-glucoside and luteolin 7-glucoside direct human hematopoietic stem cell differentiation towards erythroid lineage. Differentiation 2015, 89, 146-155. [CrossRef]

15. Ahmad-Qasem, M.H.; Cánovas, J.; Barrajón-Catalán, E.; Carreres, J.E.; Micol, V.; García-Pérez, J.V. Influence of olive leaf processing on the bioaccessibility of bioactive polyphenols. J. Agric. Food Chem. 2014, 62, 6190-6198. [CrossRef]

16. Cruz, R.M.S.; Brito, R.; Smirniotis, P.; Nikolaidou, Z.; Vieira, M.C. Extraction of bioactive compounds from olive leaves using emerging technologies. In Ingredients Extraction by Physicochemical Methods in Food, 1st ed.; Grumezescu, A., Holban, A.-M., Eds.; Elsevier Inc.: Amsterdam, The Netherlands, 2017; Volume 4, pp. 441-461.

17. Daso, A.P.; Okonkwo, O.J. Conventional extraction techniques: Soxhlet and liquid-liquid extractions and evaporation. Anal. Sep. Sci. 2015, 5, 1437-1468. [CrossRef] 
18. Lama-Muñoz, A.; Contreras, M.M.; Espínola, F.; Moya, M.; de Torres, A.; Romero, I.; Castro, E. Extraction of oleuropein and luteolin-7-O-glucoside from olive leaves: Optimization of technique and operating conditions. Food Chem. 2019, 293, 161-168. [CrossRef]

19. Šoštarič, M.; Klinar, D.; Bricelj, M.; Golob, J.; Berovič, M.; Likozar, B. Growth, lipid extraction and thermal degradation of the microalga Chlorella vulgaris. New Biotechnol. 2012, 29, 325-331. [CrossRef]

20. Borić, M.; Puliyalil, H.; Novak, U.; Likozar, B. An intensified atmospheric plasma-based process for the isolation of the chitin biopolymer from waste crustacean biomass. Green Chem. 2018, 20, 1199-1204. [CrossRef]

21. Bajić, M.; Jalšovec, H.; Travan, A.; Novak, U.; Likozar, B. Chitosan-based films with incorporated supercritical $\mathrm{CO}_{2}$ hop extract: Structural, physicochemical, and antibacterial properties. Carbohydr. Polym. 2019, 219, 261-268. [CrossRef]

22. Chemat, F.; Rombaut, N.; Sicaire, A.-G.; Meullemiestre, A.; Fabiano-Tixier, A.-S.; Abert-Vian, M. Ultrasound assisted extraction of food and natural products. Mechanisms, techniques, combinations, protocols and applications. A review. Ultrason. Sonochem. 2017, 34, 540-560. [CrossRef]

23. Cifá, D.; Skrt, M.; Pittia, P.; Di Mattia, C.; Ulrih, N.P. Enhanced yield of oleuropein from olive leaves using ultrasound-assisted extraction. Food Sci. Nutr. 2018, 6, 1128-1137. [CrossRef]

24. Shirzad, H.; Niknam, V.; Taheri, M.; Ebrahimzadeh, H. Ultrasound-assisted extraction process of phenolic antioxidants from Olive leaves: A nutraceutical study using RSM and LC-ESI-DAD-MS. J. Food Sci. Technol. 2017, 54, 2361-2371. [CrossRef]

25. Irakli, M.; Chatzopoulou, P.; Ekateriniadou, L. Optimization of ultrasound-assisted extraction of phenolic compounds: Oleuropein, phenolic acids, phenolic alcohols and flavonoids from olive leaves and evaluation of its antioxidant activities. Ind. Crop. Prod. 2018, 124, 382-388. [CrossRef]

26. Martínez-Patiño, J.C.; Gullón, B.; Romero, I.; Ruiz, E.; Brnčić, M.; Žlabur, J.Š.; Castro, E. Optimization of ultrasound-assisted extraction of biomass from olive trees using response surface methodology. Ultrason. Sonochem. 2019, 51, 487-495. [CrossRef]

27. Goldsmith, C.D.; Vuong, Q.V.; Stathopoulos, C.E.; Roach, P.D.; Scarlett, C.J. Ultrasound increases the aqueous extraction of phenolic compounds with high antioxidant activity from olive pomace. LWT-Food Sci. Technol. 2018, 89, 284-290. [CrossRef]

28. Roselló-Soto, E.; Koubaa, M.; Moubarik, A.; Lopes, R.P.; Saraiva, J.A.; Boussetta, N.; Grimi, N.; Barba, F.J. Emerging opportunities for the effective valorization of wastes and by-products generated during olive oil production process: Non-conventional methods for the recovery of high-added value compounds. Trends Food Sci. Technol. 2015, 45, 296-310. [CrossRef]

29. Di Khanh, N. Advances in the extraction of anthocyanin from vegetables. J. Food Nutr. Sci. 2015, 3, $126-134$. [CrossRef]

30. Arabi, M.; Ghaedi, M.; Ostovan, A. Development of dummy molecularly imprinted based on functionalized silica nanoparticles for determination of acrylamide in processed food by matrix solid phase dispersion. Food Chem. 2016, 210, 78-84. [CrossRef]

31. Medina-Torres, N.; Ayora-Talavera, T.; Espinosa-Andrews, H.; Sánchez-Contreras, A.; Pacheco, N. Ultrasound assisted extraction for the recovery of phenolic compounds from vegetable sources. Agronomy 2017, 7, 47. [CrossRef]

32. Şahin, S.; Şaml, R. Optimization of olive leaf extract obtained by ultrasound-assisted extraction withresponse surface methodology. Ultrason. Sonochem. 2013, 20, 595-602. [CrossRef]

33. İlbay, Z.; Şahin, S.; Büyükkabasakal, K. A novel approach for olive leaf extraction through ultrasound technology: Response surface methodology versus artificial neural networks. Korean J. Chem. Eng. 2014, 31, 1661-1667. [CrossRef]

34. Wang, B.; Qu, J.; Luo, S.; Feng, S.; Li, T.; Yuan, M.; Huang, Y.; Liao, J.; Yang, R.; Ding, C. Optimization of ultrasound-assisted extraction of flavonoids from olive (Olea europaea) leaves, and evaluation of their antioxidant and anticancer activities. Molecules 2018, 23, 2513. [CrossRef]

35. Japón-Luján, R.; Luque-Rodríguez, J.M.; Luque de Castro, M.D. Dynamic ultrasound-assisted extraction of oleuropein and related biophenols from olive leaves. J. Chromatogr. A 2006, 1108, 76-82. [CrossRef]

36. Vidal, A.M.; Alcalá, S.; Ocaña, M.T.; De Torres, A.; Espínola, F.; Moya, M. Modeling of volatile and phenolic compounds and optimization of the process conditions for obtaining balanced extra virgin olive oils. Grasas Aceites 2018, 69, e250. [CrossRef] 
37. Chang, C.C.; Yang, M.H.; Wen, H.M.; Chern, J.C. Estimation of total flavonoid content in propolis by two complementary colorimetric methods. J. Food Drug Anal. 2002, 10, 178-182.

38. Vázquez-Roncero, A.; Janer del Valle, C.; Janer del Valle, M.L. Determinación de los polifenoles totales del aceite de oliva. Grasas Aceites 1973, 24, 350-357.

39. Giacometti, J.; Žauhar, G.; Žuvić, M. Optimization of ultrasonic-assisted extraction of major phenolic compounds from olive leaves (Olea europaea L.) using response surface methodology. Foods 2018, 7, 149. [CrossRef]

40. Ameer, K.; Shahbaz, H.M.; Kwon, J.-H. Green extraction methods for polyphenols from plant matrices and their byproducts: A review. Compr. Rev. Food Sci. Food Saf. 2017, 16, 295-315. [CrossRef]

41. Carrera, C.; Ruiz-Rodríguez, A.; Palma, M.; Barroso, C.G. Ultrasound assisted extraction of phenolic compounds from grapes. Anal. Chim. Acta 2012, 732, 100-104. [CrossRef]

42. Bilgin, M.; Şahin, S. Effects of geographical origin and extraction methods on total phenolic yield of olive tree (Olea europaea) leaves. J. Taiwan Inst. Chem. E. 2013, 44, 8-12. [CrossRef]

43. Ahmad-Qasem, M.H.; Cánovas, J.; Barrajón-Catalán, E.; Micol, V.; Cárcel, J.A.; García-Pérez, J.V. Kinetic and compositional study of phenolic extraction from olive leaves (var. Serrana) by using power ultrasound. Innov. Food Sci. Emerg. Technol. 2013, 17, 120-129. [CrossRef]

(C) 2019 by the authors. Licensee MDPI, Basel, Switzerland. This article is an open access article distributed under the terms and conditions of the Creative Commons Attribution (CC BY) license (http://creativecommons.org/licenses/by/4.0/). 